\title{
Arthroscopic ACL Ligamentoplasty by Endobutton Using Hamstring Grafts
}

El Ghadraoui R*, Bensassi A, Maanouk R, Boughzala W, Madani A, Jarbouh R, El Idrissi M, EL Ibarhimi A, ElMrini A, Kada O

Orthopedic Service, Centre hospitalier de Gonesse, Paris, France

DOI: $10.36347 /$ sasjs.2020.v06i10.010

| Received: 09.10.2020 | Accepted: 21.10.2020 | Published: 30.10 .2020

*Corresponding author: EL GHADRAOUI Redouane

\section{Abstract}

This is a retrospective analysis of 35 patients admitted in the Traumato-Orthopedics department of the Gonesse Hospital Center - Paris, operated for ACL rupture by arthroscopic ligamentoplasty using the internal rectus and semitendinosus tendons by endobutton. The interest of this study is to present the principles of this surgical technique and to evaluate its results by comparing them with other knee ligamentoplasty techniques. These are mainly young patients, most of whom have been the victim of a sports accident. Magnetic resonance imaging (MRI) enabled the diagnosis. Postoperatively, early passive rehabilitation was prescribed for our patients with progressive flexion angles. Our functional results, assessed by the scores of Lysholm and IKDC, were satisfactory with an almost total resumption of sports and professional activities.

Keywords: ACL ligamentoplasty, hamstring grafts, arthroscopy, endobutton.

Copyright $(\mathcal{C} 2020$ The Author(s): This is an open-access article distributed under the terms of the Creative Commons Attribution 4.0 International License (CC BY-NC 4.0) which permits unrestricted use, distribution, and reproduction in any medium for non-commercial use provided the original author and source are credited.

\section{INTRODUCTION}

The anterior cruciate ligament (ACL) plays a critical role as a primary knee stabilizer, its rupture is a frequent accident for young athletes with an annual incidence in France of 80,000 cases.

The aim of the ACL ligamentoplasty is to correct the anterior laxity by reconstituting a neoligament, to regain a stable, painless and functional knee, while avoiding the long-term risks of osteoarthritis [1].

There have been many technical and scientific developments in the field of ACL surgery in recent decades. Arthroscopy has enabled ACL reconstruction techniques to become reliable and reproducible, particularly ligamentoplasty using ha hamstrings grafts.

\section{MATERIALS AND METHODS}

Our work is a retrospective analysis of 35 cases of arthroscopic ACL ligamentoplasty using hamstrings grafts by endobutton collected at the orthopedics department of the Centre Hospitalier de Gonesse - Paris, between January 2017 and January 2019. The objective is to assess the results of this surgical technique and present its principles.
All our patients underwent a standard x-ray of the knee, face and profile, and an MRI which confirmed the diagnosis. The patients were operated by three different surgeons using the same technical principles: a first step for open DIDT harvesting then an arthroscopic step allowing fixation of the "four strands" graft with endobutton on the femur and an interference screw on the tibia "in-out". The average time between the accident and surgery was 11 months.

The average length of hospital stay in our study was 02 days. An articulated knee brace with immediate rehabilitation of the knee was maintained, started early but gradually concerning the kne eangles of flexion. We saw our patients again at 45 days, 03 months and then every 06 months, a radio-clinical consultation based on the functional IKDC and Lysholm / Tenger score as well as a front and side view $\mathrm{x}$-ray.

\section{RESULTS}

This is a retrospective study that involved 35 patients whose average age was 30.2 years (with extremes of 18 to 45 years), with a male predominance of $80 \%$ (Sex Ratio = 4). The initial trauma was a sport accident in $71 \%$ of cases, a road accident in $23 \%$ and a work accident in $06 \%$. The mechanism of injury frequently encountered was a flexion external rotation 
valgus in $45.7 \%$ of cases. The right knee was still the most affected (77\%). Subjective and objective laxity was present for all patients with a positive Lachmann and anterior drawer test for all patients, peripheral internal laxity for 05 patients. The standard x-ray did not show signs of osteoarthritis or pre-osteoarthritis.

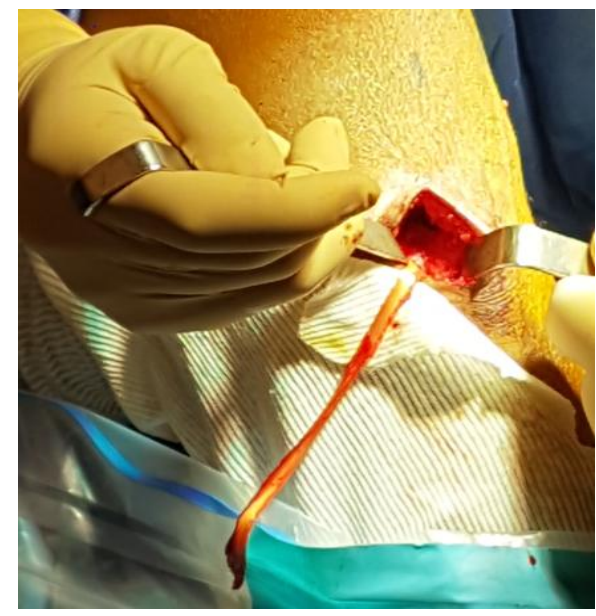

Fig-01: Patient installation

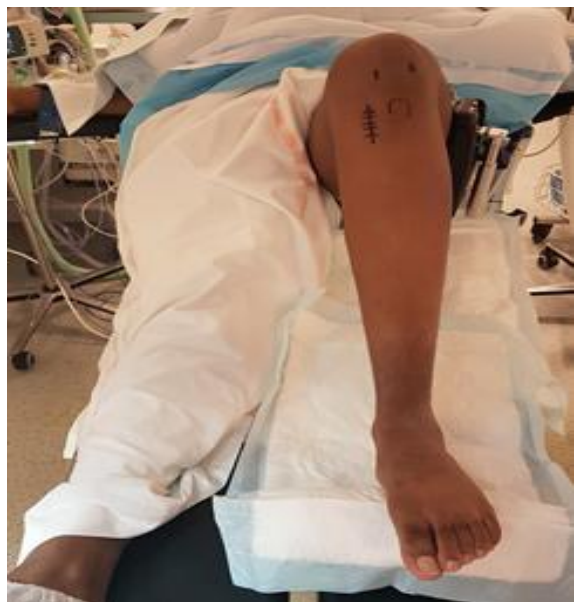

Fig-02: Taking out the transplant

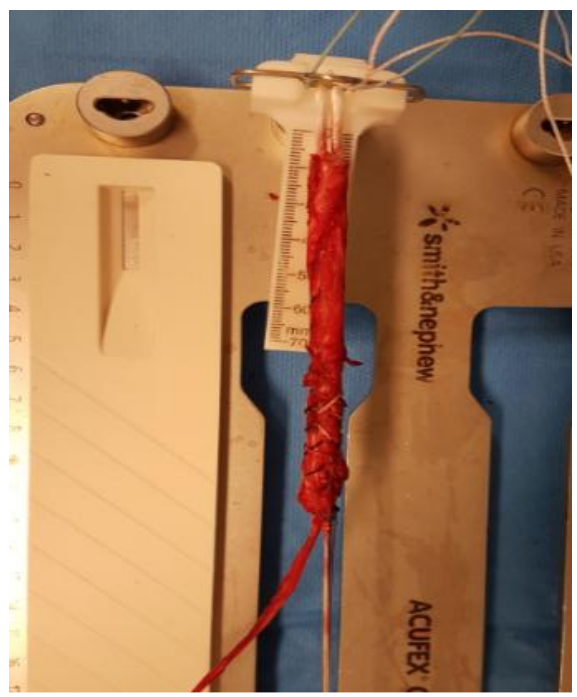

Fig-03: Threading the transplant
MRI showed total interstitial ACL rupture in all patients, associated with meniscal lesions for 08 patients, $60 \%$ internal and $40 \%$ external. Meniscal suture was performed to 05 patients, while meniscal regularization was necessary for 03 patients.

The femoral fixation (fig 04) was made by an endobutton, in the tibial the fixation was ensured by an absorbable interference screw. The mean overall preoperative score according to Lysholm fell from 66.5 to 95 postoperatively. With an average follow-up of 28 months, the overall results were evaluated according to the IKDC score, they were excellent and good in $92 \%$ of cases. We did not note any difference between surgeons with a satisfactory reduction in pain and a resumption of usual sports activity 12 months after surgery. $80 \%$ of our sports patients have recovered to a level similar to that before the trauma.
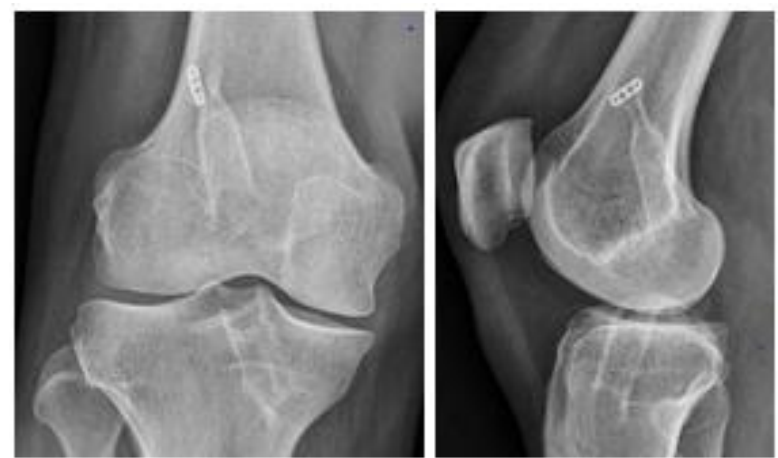

Fig-04: Post opérative front and side view $x$-ray of knee

In our series, no intraoperative incident or conversion to open surgery were reported. No immediate postoperative complications were noted to our patients, including no case of surgical site infection, thromboembolic complication or osteoarthritis.

\section{DISCUSSION}

ACL reconstruction surgery is one of the most common types of knee surgery today. Arthroscopy has undeniable advantages, in fact it allows: a complete joint assessment, diagnosis and treatment of meniscal and osteo-chondral lesions at the same time of operation, better visualization of the transplant insertion areas, more high speed of postoperative and recovery [3].

Currently, two transplants are widely used: the patellar tendon (Kenneth Jones : KJ) and the hamstring tendons (DIDT), with identical results. Nevertheless, the macrostructure of the two grafts is very different: the first is a quadrilateral monobloc osteotendinous transplant to the cut while the hamstrings form a purely multi-fasciculated tendon transplant where each bundle is cylindrical. 
Zaalouni and $\mathrm{Al}$ [3], by comparing these two techniques, objected to better functional results and a delay in returning to sport in favor of hamstring grafts (fig 05 and 06):

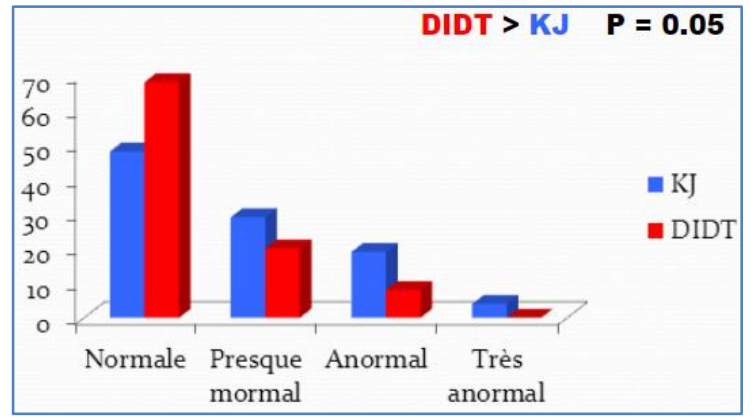

Fig-05: DIDT superiority in returning to sport

\begin{tabular}{|c|c|c|c|}
\hline & $\mathrm{KJ}$ & DIDT & \multirow{3}{*}{$\begin{array}{c}\text { NS } \\
P=0,27\end{array}$} \\
\hline$\%$ des patients & $61 \%$ & $70 \%$ & \\
\hline Délai moyen & 11 mois & 9 mois & \\
\hline
\end{tabular}

Fig-06: Postoperative subjective impression

The results of a meta-analysis of prospective studies with more than 2 years of follow-up comparing the two techniques found a resumption of sport at the same level, the IKDC score laxity, the number of failures and the overall IKDC score $n$ were not statistically different between the two types of transplants. Anterior knee pain is more present in KJs [4].
Matsumoto as well as Katabi [5] concluded in their published work with somewhat similar results by comparing TR and DIDT grafts, with a superiority of the second technique in terms of:

- Less residual pain.

- Simpler postoperative consequences.

- Best results for the IKDC.

- Aesthetic scar.

- Better functional recovery.

- Less quadriceps muscular atrophy.

Rehabilitation is recommended preoperatively in order to recover good range of motion and good muscle control, because the muscle work done before the operation promotes the awakening of the quadriceps immediately postoperatively. It must take into account the phenomena of ligamentization and the mechanical stresses exerted on the various compartments of the knee during rehabilitation [6].

The Franco-Belgian Tape Locking Screw (TLS) technique based on a short graft of a single tendon is an interesting alternative to traditional harvesting with good functional results [7].

\section{CONCLUSION}

In agreement with the majority of authors, ACL ligamentoplasty with DIDT by endobutton concludes at very good functional results with a reduction in the anterior knee pain and a satisfactory resumption of activities.

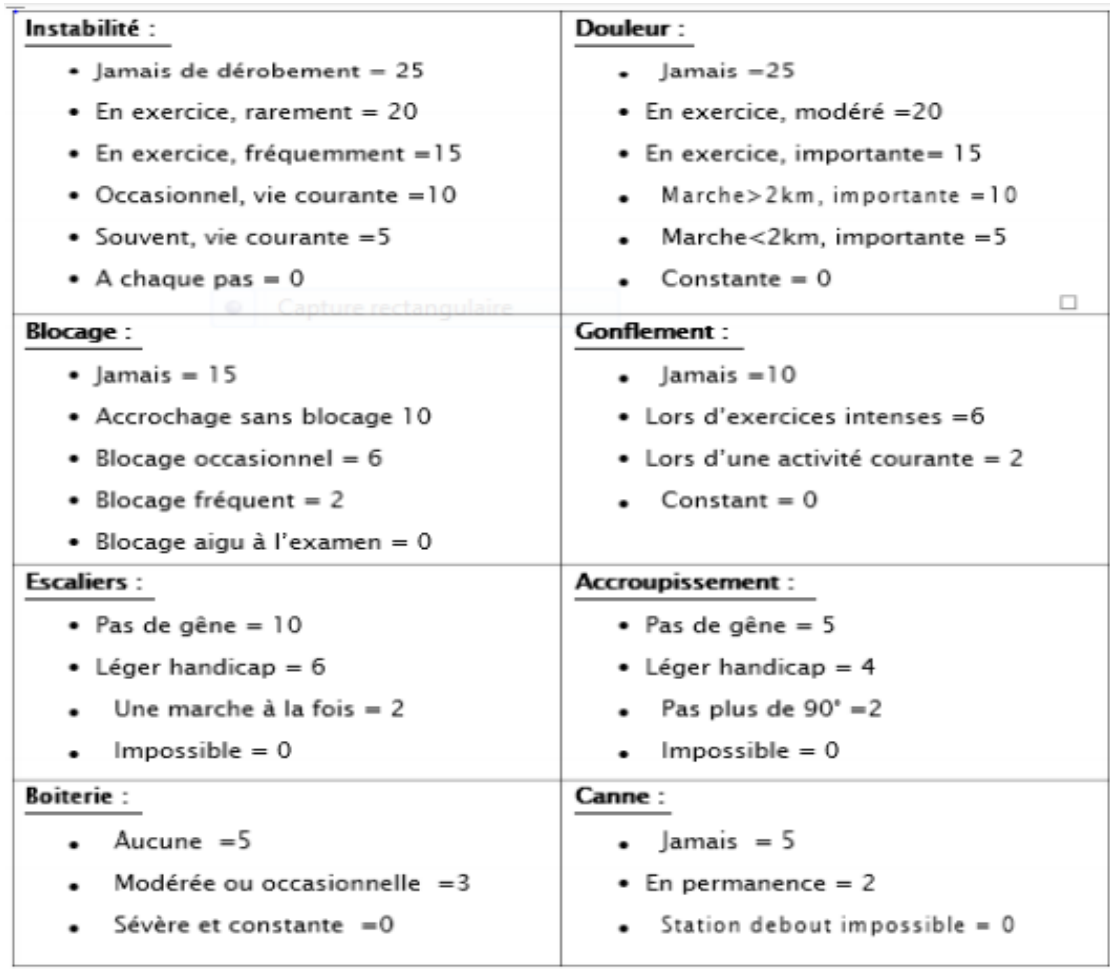

Lysholm and Tegner Score 


\section{REFERENCE}

1. Colvin A, Sharma C, Parides M, Glashow J. What is the best femoral fixation of hamstring autografts in anterior cruciate ligament reconstruction? a meta-analysis. Clin Orthop Relat Res. Avr. 2011;469(4):1075-81.

2. Yahyaoui M, Agoumi O, Najib A, Daoudi A, Yacoubi H. Nº73 Spécial Congrès SMA. 2018: 1519

3. Benkacem I. Résultats comparatifs de ligamentoplastie du LCA par TLS/DIDT
4. Rochcongar G, Cucurulo T, Ameline T, Potel J-F, Dalmay F, Laporte C, Seil R, Gunepin F-X, la Société française d'arthroscopie. 2015: S296-S300

5. Katabi M, Dijan P. Christel Revue de Chirurgie Orthopédique; 2002.

6. Laboute E, Savalli L, Lefesvre T, Puig P, Trouve P. Intérêt d'une rééducation spécialisée à distance d'une chirurgie du ligament croisé antérieur chez le sportif de haut niveau. Revue de chirurgie orthopédique et réparatrice de l'appareil moteur. 2008 Oct 1;94(6):533-40

7. Benkacem I. Résultats comparatifs de ligamentoplastie du LCA par TLS/DIDT. 